\title{
Efficacy of Local Isolate of Beauveria bassiana and Commercial Product of B. Bassiana Mixed with Metarhizium anisopliae on the Greater Wax Moth Dina M. Fathy ${ }^{1}$; H. M. Fathy ${ }^{1}$; H. M. Mansour ${ }^{2}$ and M. A. R. Ziedan ${ }^{2}$ ${ }^{1}$ Department of Economic Entomology, faculty of Agriculture, Mansoura University, Egypt ${ }^{2}$ Apiculture department, Plant Protection Research Institute, Egypt
} E-mail : dinahuha12@gmail.com

\section{ABSTRACT}

The efficiency of local isolate of Beauveria bassiana indigenous in Egy pt, was estimated compared with the bio-pesticide (mixture of B. bassiana and Metarhizium anisopliae ) on the greater wax moth (GWM), Galleria mellonella L. Five concentrations of $B$. bassiana $\left(1 \times 10^{7}, 2.5 \times 10^{7}, 5 \times 10^{7}, 7.5 \times 10^{7}\right.$ and $1 \times 10^{8}$ conidia/ml $)$ and the biopesticide, $(2,4,6,8$ and $10 \mathrm{~g} / \mathrm{L})$ against $G$. mellonella larvae were evaluated understorage conditions. B. bassiana was reared in two media ( PDA and mummies of GWM larvae). The fungal isolate, Beauveria bassiana at all tested concentrations affect the mortality of $G$. mellonela larvae, especially at the highest concentration. The obtained data obviously indicated that, fungal isolate (grown on mummies of GWM) exhibited a relatively high effect on G. mellonella larvae in comp arison with that reared on PDA media. However, after 21 days of treatment $B$. bassiana reared on GWM larvae caused, $46.33 \pm 17.9,63.33 \pm 11.6,70 \pm 00,70 \pm 20$ and $86.66 \pm 11.6 \%$ mortality, while, $B$. bassiana grown on PDA caused, $40 \pm 12.5,50 \pm 16.0$ $73.33 \pm 24.3,53.33 \pm 24.2$ and $80 \pm 26.3 \%$ mortality of the treated larvae at the concentrations of $1 \times 10^{7}, 2.5 \times 10^{7}, 5 \times 10^{7}, 7.5 \times 10^{7}$ and $1 \times 10^{8}$ conidia/ml, respectively. At the highest concentration $(10 \mathrm{~g} / \mathrm{L})$ of the bio-insecticides the mortality percentages of treated $G$. mellonela larvae were $40 \pm 16.4,66.66 \pm 24.2,76.66 \pm 27.6$ and $83.33 \pm 27.2 \%$, after $6,9,12$ and 15 days of treatment, respectively.

Keywords; Galleria mellonella, entomopathogenic fungi, Beauveria bassiana, Metarhizium anisopliae, control.

\section{INTRODUCTION}

The greater wax moth, Galleria mellonella L. (Lepidoptera: Pyralidae) is considered a trouble in honeybee colonies. This pest is usually appeared in combs of weak or dead bee colonies and in stored combs. This pest can't attack combs in active honey bee colonies (Ellis et al., 2013). Besides, damaging waxcombs, G. mellonella larvae fed on stored pollen, destroying frames and wooden parts in the hive. The moth larvae caused gallerias is (The bee pupae in the cells are rarely damaged, but sometimes become trapped in the cells by the silk threads and die). Adult waxmoths and larvae may also transfer pathogens of serious bee diseases, e.g. foulbrood. However, in colonies infected with this disease, feces of the wax moth contain large amounts of spores of the causative bacteria Paenibacillus (Krams et al., 2015) and the potential of transmitting honeybee viruses has raised legitimate concern. Most of investigated by transversal sections in the mid-gut to entomopathogenic fungi belong to Deuteromycetes. B. bassiana infected successfully larvae, pupae and adults of many insects and at the time of insect death nearly all of the internal organs of the insect are utilized by the fungus (Tanada and keya 1993). Beauveriabassiana is ubiquitous fungus which has been found and is olated froma wide variety of insects of different orders and is the most widely used fungal species available commercially (Mansour, 1991; Zimmermann, 2007; Goettel et al., 2010 and Ibrahim et al., 2016). According to Vey et al., (2001) B. bassiana produces several toxic compounds in vitro and in vivo. So, the present study aims to evaluate the efficiency of local isolate of B. bassiana compared with the commercial product (Care Protector) of fungi mix (B.bassiana and M. anisopliae) against the wax moth in the storage.

\section{MATERIALS AND METHODS}

The efficiency of local is olate of entomopathogenic fungi (i. e. Beauveria bassiana), indigenous in Egypt, previously isolated and identified by (El Sheikh, 2003) from the greater waxmoth (GWM), Galleria mellonella L. larvae at different regions of the Nile-Delta was estimated compared with the commercial product (fungi mix) on the larvae of GWM. These experiments were carried out under storage conditions in the apiary of Beekeeping Research section at Sakha Agriculture Research Station, Kafr El-Sheikh.

\section{1-Tested entomopathogenic fungi:}

Local isolate of Beauveria bassiana

To have colonies of $B$. bassiana, the fungi was grown on G. mellonella larvae and PDA media.

\section{On G. mellonella larvae :}

The fungus was cultured on G. mellonella larvae as described by Mansour (1999).

\section{On PDA media:-}

Potato dextrose agar medium was a suitable media for culturing B. bassiana .

For fungal inoculums preparation, inoculations of the fungal isolates were prepared by growing them without shaking in conical flasks $(250 \mathrm{ml})$ containing potato dextrose (PDA) broth mediumat $28^{\circ} \mathrm{C}$ for 15 days. The fungal mas ses were blended and the concentration was adjusted to $10^{8}$ conidia/ml (Mansour, 1991 and Saleh , 2002).

\section{- The bio-pesticide (Care Protector):}

The bio- pesticide is a commercial product containing (1-2\% B. bassiana WP- $1 \times 10^{9} \mathrm{CFU} / \mathrm{gm}, M$. anisopliae WP- $2 \times 10^{8} \mathrm{CFU} / \mathrm{gm}$, carrier powder $85-90 \%$ and Moisture 5-10\%).

1. Pathogenicity of B. bassiana isolate to GWM under storage conditions :-

This experiment was carried out to evaluate the pathogenecity of B. bassiana grown on the larvae of $G$. mellonella and PDA mediumto G. mellonella under storage conditions in the apiary of Beekeeping Research section at Sakha Agriculture Research Station, Kafr El-Sheikh.

Each prepared inoculums was used with five concentrations $\left(1 \times 10^{7}, 2.5 \times 10^{7}, 5 \times 10^{7}, 7.5 \times 10^{7}\right.$ and $1 \times 10^{8}$ conidia/ml) (the lowest four were prepared by dilution the highest concentration by water). $0.1 \%$ Tween 80 was added for each suspension.

Eighteen old wax combs (dark colored) were selected from the apiary store and kept in the oven at $45^{\circ} \mathrm{C}$ for 72 hours to destroying any infestation with the greater wax moth larvae. Then, selected wax combs were infected with freshly fifth instars larvae of $G$. mellonella (ten individuals/ comb). After three hours, each comb was sprayed on both faces with $10 \mathrm{ml}$ of the fungus suspension using an automizer (three wax combs as replicates for each concentration). In addition, three frames were sprayed with water containing $0.1 \%$ Tween 80 (as a check). All wax combs were kept in swarmbox and placed in the storage where the temperature ranged from $22^{\circ} \mathrm{C}$ to $26^{\circ} \mathrm{C}$ and the relative humidity was 65 to $70 \%$ R.H. After $6,9,12,15,18$ and 21 days of treatment, treated and check frames were examined and the number of dead G. mellonella larvae was counted and recorded.

2. Pathogenicity of the bio Pesticide containing mixture of B. bassiana and Metarhizium anisopliae): Five dilutions of the bio Pesticide, (Care Protector) in distilled water were prepared as follow: $(2,4,6,8$ and 
$10 \mathrm{~g} / \mathrm{L})$. Eighteen old waxcombs infected with GWM larvae was treated as previously mentioned. After 6, 9, 12 and 15 days of treatment, treated and untreated frames were examined and the number of dead larvae was counted and recorded. The efficacy of each treatment was calculated according to the formula described by (Soliman 2005).

\section{Percentage of efficacy $=\frac{\mathrm{Ta}-\mathrm{Ca}}{100-\mathrm{C}} \mathrm{100}$ where $100-\mathrm{Ca}$}

$\mathrm{Ca}=$ Number of dead larvae in the control after treatment. $\mathrm{Ta}=$ Number of dead larvae in the treated bee wax after the application of different treatments.

\section{Statistical analysis}

All experiments were repeated twice with three replicates of each concentration or treatment. All data were subjected to one-way analys is of variance (ANOVA) and significant differences between treatment means were determined using Tukey's HSD test at $\mathrm{P}<0.05$. The data were analyzed by SAS (version 9.1, SAS Institute, Cary, NC, USA)

\section{RESULTS AND DISCUSSION}

\section{Efficiency of $B$. bassiana isolate against $G$. mellonela} larvae.

\section{B. bassiana reared on PDA.}

The results are summarized in Table (1). The fungal isolate, Beauveria bassiana at all tested concentrations affect the mortality of $G$. mellonela larvae, es pecially at the highest concentration. However, after 6, 9, 12 and 15 days of treatment the mortality percentages of GWM larvae were $20 \pm 6.97,43.3 \pm 13.54,70 \pm 24.35$ and $80 \pm 25.17 \%$ at the concentrations of $1.0 \times 10^{8}$ conidia/ml, respectively. At the concentration of $1.0 \times 10^{7}$ conidia/ml , B. bassiana caused a slight mortality of $G$. mellonela larvae.

The mortality rate was significantly increased by time. The highest effect was recorded after 15 days of treatment at all concentrations. At $5 \times 10^{7} \mathrm{con} . / \mathrm{ml}$., the mortality percentage reached to $73.33 \pm 24.31$ after 21 days of treatment.

Table 1. Pathogenicity of Beauveria bassiana isolate grown on PDA to the fifth larval instars of G. mellonella under storage conditions at different inoculums densities (concentrations) of fungi.

\begin{tabular}{|c|c|c|c|c|c|c|}
\hline \multirow{2}{*}{$\begin{array}{l}\text { Inoculums } \\
\text { densities }\end{array}$} & \multicolumn{6}{|c|}{ Mortality \% at different inoculums densities after } \\
\hline & 6 days & 9 days & 12 days & 15 days & 18 days & 21 \\
\hline$\overline{1 \times 10^{7}}$ & $6.66 \pm 4.7 \mathrm{bc}$ & $20 \pm 9.8 b$ & $23.33 \pm 13.7 \mathrm{~cd}$ & $33.33 \pm 15.5 \mathrm{c}$ & $36.66 \pm 6 b c a$ & $40 \pm 12.5 b$ \\
\hline $2.5 \times 10^{7}$ & $10 \pm 3.7 \mathrm{abc}$ & $30 \pm 10.0 \mathrm{ab}$ & $36.66 \pm 13.3 \mathrm{bc}$ & $43.33 \pm 14.6 b c$ & $46.66 \pm 15.2 \mathrm{ba}$ & $50 \pm 16.0 \mathrm{ab}$ \\
\hline $5 \times 10^{7}$ & $13.33 \pm 4.9 \mathrm{ab}$ & $30 \pm 10.7 \mathrm{ab}$ & $53.33 \pm 18.4 \mathrm{ab}$ & $63.33 \pm 20.6 \mathrm{ab}$ & $70 \pm 22.6 \mathrm{bca}$ & $73.33 \pm 24.3 \mathrm{a}$ \\
\hline $7.5 \times 10^{7}$ & $13.33 \pm 5.2 \mathrm{ab}$ & $30 \pm 10.8 \mathrm{ab}$ & $60 \pm 22.2 \mathrm{ab}$ & $50 \pm 21.2 b c$ & $53.33 \pm 23.2 \mathrm{ba}$ & $53.33 \pm 24.2 \mathrm{ab}$ \\
\hline $1 \times 10^{8}$ & $20 \pm 7.0 a$ & $43.3 \pm 13.5 a$ & $70 \pm 24.4 \mathrm{a}$ & $80 \pm 25.2 \mathrm{a}$ & $80 \pm 25.8 \mathrm{ca}$ & $80 \pm 26.3 a$ \\
\hline Control & $0.00 \pm 0.0 \mathrm{c}$ & $0.00 \pm 0.0 \mathrm{c}$ & $0.00 \pm 0.0 \mathrm{~d}$ & $0.00 \pm 0.0 \mathrm{~d}$ & $00.0 \pm 0.0 \mathrm{~d}$ & $0.00 \pm 0.0 \mathrm{c}$ \\
\hline$\underline{\mathrm{LSD}}$ & 10.27 & 16.77 & 28.13 & 28.13 & 29.94 & 31.38 \\
\hline
\end{tabular}

Means followed by different letters are significantly different according to $\operatorname{LSD}(\mathbf{P}=.05)$.

\section{B. bassiana reared on G. mellonella larvae.}

The obtained data, as shown in Tables (2), obviously indicated that, fungal isolate (grown on mummies of GWM) exhibited a relatively high effect on G. mellonella larvae in comparis on with that reared on
PDA media. However, after 21 days of treatment $B$. bassiana caused, 46.33 $\pm 17.9,63.33 \pm 11.6,70 \pm 00,70 \pm 20$ and $86.66 \pm 11.6 \%$ mortality of the treated larvae at the concentrations of $1 \times 10^{7}, 2.5 \times 10^{7}, 5 \times 10^{7}, 7.5 \times 10^{7}$ and $1 \times 10^{8}$ conidia/ml, respectively.

Table 2. Pathogenicity of Beauveria bassiana isolate grown on GWM larvae to the fifth larval instars of $G$. mellonella under storage conditions at different inoculums densities (concentrations) of fungi.

\begin{tabular}{|c|c|c|c|c|c|c|}
\hline \multirow{2}{*}{ Concentration ./ml } & \multicolumn{6}{|c|}{ Mean no. of dead GWM larvae after time intervals (days) } \\
\hline & 6 & 9 & 12 & 15 & 18 & 21 \\
\hline$\overline{1 \mathrm{x} 10^{\prime}}$ & $3.33 \pm 4.9 \mathrm{ab}$ & $10 \pm 4.4 c$ & $20 \pm 9.1 c$ & $40 \pm 14.9 \mathrm{c}$ & $43.33 \pm 15.8 \mathrm{c}$ & $46.33 \pm 17.9 \mathrm{bca}$ \\
\hline $2.5 \times 10^{7}$ & $3.33 \pm 4.5 \mathrm{ab}$ & $13.33 \pm 5.2 \mathrm{bc}$ & $26.66 \pm 9.1 \mathrm{c}$ & $50 \pm 16.5 b c$ & $53.33 \pm 18.4 b c$ & $63.33 \pm 11.6 \mathrm{bc}$ \\
\hline $5 \times 10^{7}$ & $3.33 \pm 4.4 \mathrm{ab}$ & $10 \pm 4.4 \mathrm{c}$ & $30 \pm 9.4 c$ & $56.66 \pm 17.6 b$ & $66.66 \pm 20.7 \mathrm{ab}$ & $70 \pm 00 \mathrm{ab}$ \\
\hline $7.5 \times 10^{7}$ & $6.66 \pm 4.4 \mathrm{ab}$ & $20 \pm 6.9 \mathrm{ab}$ & $43.33 \pm 12.7 b$ & $56.66 \pm 18.1 b$ & $63.33 \pm 21.2 b$ & $70 \pm 20 \mathrm{ab}$ \\
\hline $1 \times 10^{8}$ & $10 \pm 4.5 a$ & $26.66 \pm 8.7 \mathrm{a}$ & $56.66 \pm 17.0 \mathrm{a}$ & $76.66 \pm 21.6 \mathrm{a}$ & $83.33 \pm 24.12 \mathrm{a}$ & $86.66 \pm 11.6 \mathrm{a}$ \\
\hline Control & $0.00 \pm 0.0 \mathrm{~d}$ & $0.00 \pm 0.00 \mathrm{~d}$ & $0.00 \pm 0.0 \mathrm{~d}$ & $0.00 \pm 0.0 \mathrm{~d}$ & $0.00 \pm 0.0 \mathrm{~d}$ & $0.00 \pm 0.0 \mathrm{~d}$ \\
\hline LSD & 8.39 & 9.38 & 12.58 & 14.53 & 18.75 & 21.788 \\
\hline
\end{tabular}

Means followed by different letters are significantly different according to LSD $(P=.05)$.

As shown in Table (1 and 2), the mortality percentage of GWM larvae was significantly increased as the inoculums densities of $B$. bassiana increase. Similar results were obtained by Mansour (2003), that there was a positive correlation between $B$. bassiana conidia concentrations $\left(2 \times 10^{7}, 4 \times 10^{7}, 8 \times 10^{7}, 1.6 \times 10^{8}\right.$ and $3.2 \times$ $10^{8} \mathrm{con} . / \mathrm{ml}$ ) and the mortality of $G$. melonella larvae in laboratory and storage condition. Who, added that at (1.6 $\times 10^{8}$ ) concentration of B. bassiana, $96 \%$ and $82 \%$ mortality was recorded after $20^{\text {th }}$ days of treatment under laboratory store conditions against $G$. melonella larvae, respectively. The present data are agree with Saleh et al. (2016) that B.bassiana, M. anisopliae and V. lecanii. were virulence of is olated fungi which tested against larvae of G. mellonella.B. bassiana caused the highest mortality in larvae as compared with other tested fungal isolates.

To evaluate the pathogenicity of B.bassiana is olate reared on PDA and G. mellonella larvae to GWM against time, regression analysis has been done between the mortality \% and time (days). Data illustrated in Figure (1a and b) showed the regression of the mortality of each concentration to GWM larvae over 21 days). Data obviously indicated that B. bassiana reared on GWM larvae caused an approximately higher rate of mortality than that of B. bassiana reared on PDA.

Regression analysis illus trated that the pathogenicity of the tested B. bassiana isolate varied according to the rearing methods and concentration. However, the efficiency of all concentrations of B. bassiana reared on GWM larvae sharply increased by the time (Fig.1 a).

On the contrary, the efficiency of all concentrations of $B$. bassiana reared on PDA was slightly increased by the time (Figure, $1 \mathrm{~b}$ ). However, the slope of regression line was $3.19,4.22,5.047,5.35$ and 5.46 (for B. bassiana reared on GWM larvae) and 1.91, 2.22, 3.7 and 3.84 (for $B$. bassiana reared on PDA at $1 \times 10^{7}, 2.5 \times 10^{7}, 5 \times 10^{7}, 7.5 \times 10^{7}$ and $1 \times 10^{8}$ conidia/ml, respectively. 


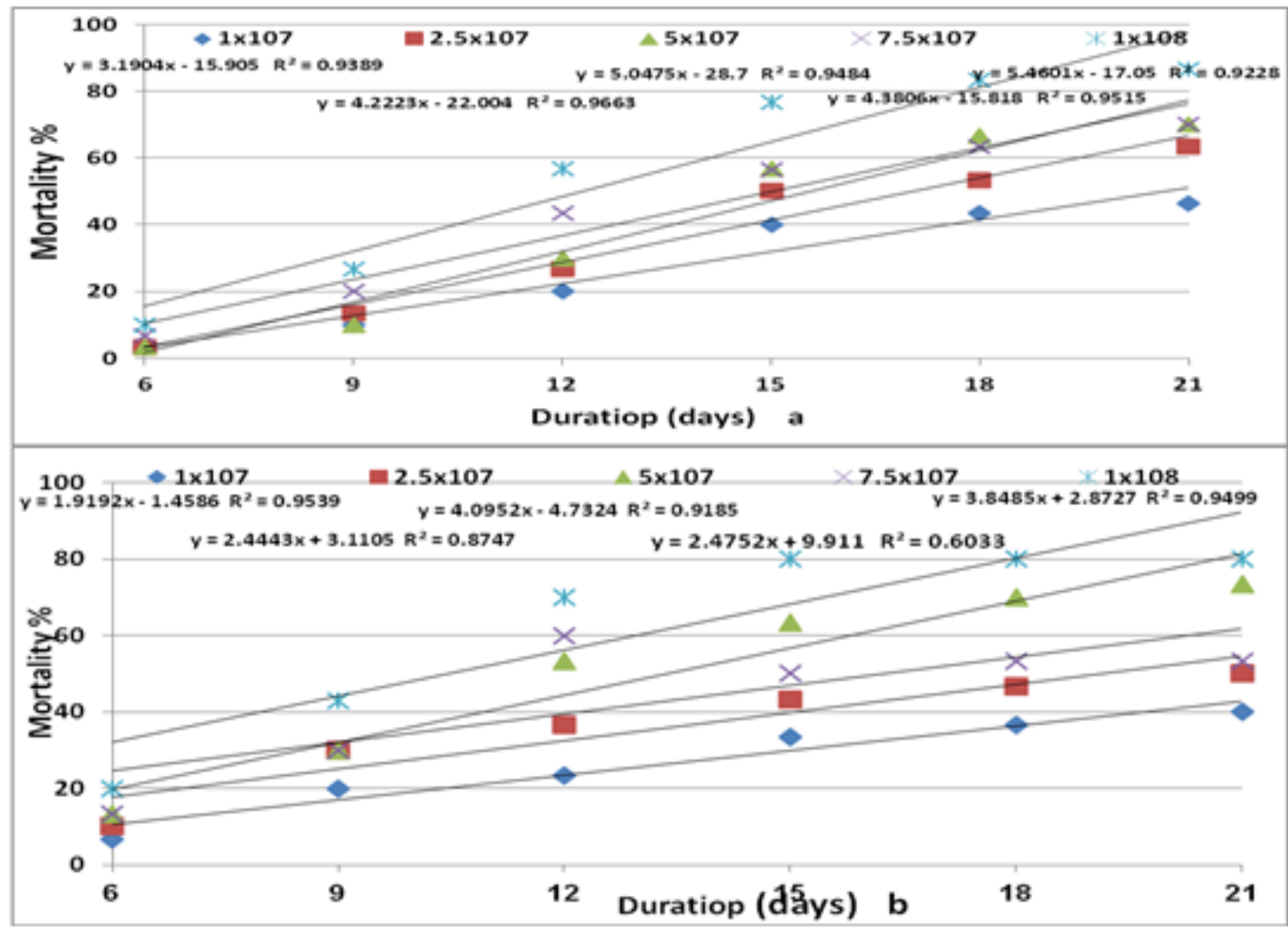

Figure (1 a and b). Stability of different inoculums densities of $B$. bassiana isolate reared on GWM larvae (a) and PDA media (b) in their pathogenecity to G. mellonella larvae over 21 days under store conditions.

From above mentioned results it could be concluded that, G. mellonella larvae is the best media for mass production of $B$. bassiana, while the best concentration of $B$. bassiana was $1 \times 10^{8}$ spore/ $\mathrm{ml}$.

2. Efficiency of the bio-pesticide (mixture of $B$. bassiana and Metarhizium anisopliae) on $G$. mellonela larvae.

The effectiveness of commercial bio-insecticide ( $B$. bassiana mix with $M$. anisopliae) (Care Protecto) was evaluated to determine the most effective concentration against G.mellonella larvae. The bio-insecticides at all tested concentrations $(2,4,6,8$ and $10 \mathrm{~g} / \mathrm{L})$ affect the mortality of G. mellonela larvae, especially at the highest concentration. However, after 6, 9, 12 and 15 days of treatment the mortality percentages of GWM larvae were $40 \pm 16.4,66.66 \pm 24.2$, $76.66 \pm 27.6$ and $83.33 \pm 27.2 \%$ at the concentrations of $10 \mathrm{~g} / \mathrm{l}$, res pectively (table 3 ). At the concentration of $2 \mathrm{~g} / 1$, the bioinsecticide caused a slight mortality of $G$. mellonela larvae, represented by $30 \pm 14.9 \%$ after 15 days .

To evaluate the pathogenicity of the bio-insecticide to GWM larvae against time, regression analysis has been done between the mortality \% and time (days).

Table 3. Mean mortality \% of G. mellonela larvae treated with mix of Beauveria bassiana and Metrahizium anisopliae under storage conditions..

\begin{tabular}{lcccc}
\hline Concentrations & \multicolumn{4}{c}{ Mean no. of dead GWM larvae after time intervals (days) } \\
\cline { 2 - 5 } Gram/L. & $\mathbf{6}$ & $\mathbf{9}$ & $\mathbf{1 2}$ & $\mathbf{1 5}$ \\
\hline $2 \mathrm{~g} / \mathrm{l}$ & $0.00 \pm 0 \mathrm{c}$ & $13.33 \pm 10.6 \mathrm{~b}$ & $16.66 \pm 11.4 \mathrm{c}$ & $30 \pm 14.9 \mathrm{c}$ \\
$4 \mathrm{~g} / \mathrm{l}$ & $20 \pm 11.4 \mathrm{~b}$ & $43.33 \pm 18.5 \mathrm{a}$ & $50 \pm 19.6 \mathrm{~b}$ & $53.33 \pm 19.4 \mathrm{~b}$ \\
$6 \mathrm{~g} / \mathrm{b}$ & $30 \pm 15.3 \mathrm{ab}$ & $50 \pm 19.8 \mathrm{a}$ & $66.66 \pm 24.7 \mathrm{ab}$ & $70 \pm 23.8 \mathrm{ab}$ \\
$8 \mathrm{~g} / 1$ & $33.33 \pm 15.5 \mathrm{ab}$ & $56.66 \pm 21.9 \mathrm{a}$ & $73.33 \pm 26.7 \mathrm{a}$ & $73.33 \pm 25.4 \mathrm{a}$ \\
$10 \mathrm{~g} / 1$ & $40 \pm 16.4 \mathrm{a}$ & $66.66 \pm 24.2 \mathrm{a}$ & $76.66 \pm 27.6 \mathrm{a}$ & $83.33 \pm 27.2 \mathrm{a}$ \\
Control & $0.00 \pm 0.0 \mathrm{c}$ & $0.00 \pm 0.0 \mathrm{~b}$ & $0.00 \pm 0.0 \mathrm{c}$ & $0.00 \pm 0.0 \mathrm{~d}$ \\
LSD & 16.77 & 24.45 & 19.66 & 17.78 \\
\hline
\end{tabular}

Means followed by different letters are significantly different according to LSD $(P=.05)$.

Data illustrated in Figure (2) showed the regression of the mortality of each concentration to GWM larvae over 15 days. Data obviously indicated that the efficiency of all concentrations of the bio-insecticide was sharply increased by the time, especially at the highest concentrations (Figure, 2). However, the slope of regression line was 3.11, 3.56, $4.55,4.56$ and 4.67 at $2,4,6,8$ and $10 \mathrm{~g} / \mathrm{L}$, respectively.

The significant times recorded which achieved the high mortality of larvae were $9^{\text {th }}$ and $12^{\text {th }}$ days after treatment (Table 3). Results indicated that the insecticidal activity of Care Protecto against G. mellonella larvae was effective as a biological control agent against larvae in the store (apiary room). These results agree with Klingen etal., (2002) that $M$ .anisopliae and B. bassiana were highly virulent to $G$. mellonella larvae and caused $100 \%$ mortality. Also, AbdelRaheemet al,. (2016) In Egypt, bioas syed B. bassiana and M. anisopliae on G.mellonlla in the laboratory. The mortality percentages of G. mellonella larvae treated with B.bassiana is olate fromElbehira reached to $100 \%$ when treated with the concentration $\left(2 \times 10^{4}\right.$ spores $\left./ \mathrm{ml}\right)$ after $7^{\text {th }}$ day and $100 \%$ mortality after $9^{\text {th }}$ day when treated with the concentration $\left(2 \times 10^{3}\right.$ and $2 \times 10^{4}$ spores/ ml) from M. anisopliae. Also, Care Protecto are effective against larval and pupal stages of wide pests of Lepidoptera, Tutta absoluta, etc.

So, Care Protecto ( mixture of B. bassiana and $M$. anisopliae) can be used as a promising agent in pest controland integrated pest management programs instead to reduce the damage of this pest. 


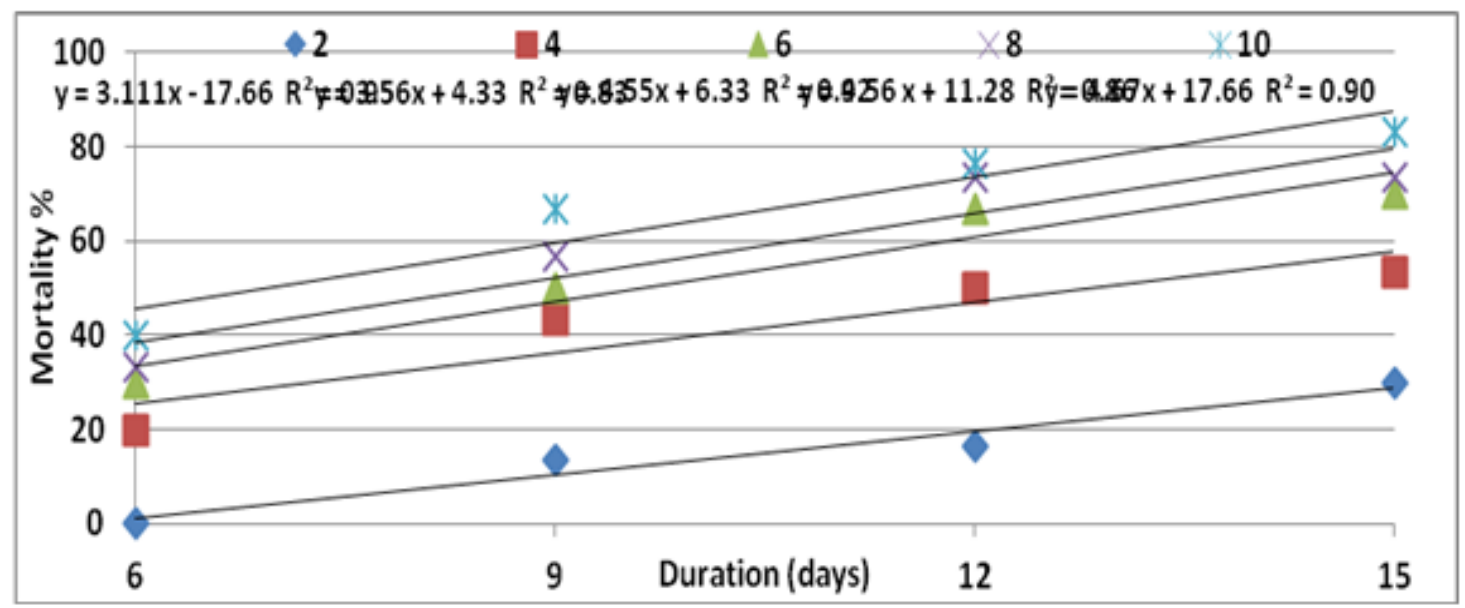

Figure 2. Stability of different concentrations of $B$. bassiana is olate reared on GWM larvae (a) and PDA media (b) in their pathogenecity to $G$. mellonella larvae over 21 days under store conditions.

\section{REFERENCES}

Abdel-Raheem M. A., I. A. Ismail; N.A. Farag; R. S. Abdel-Rahman and H. H. Elbehery (2016). Isolates, Virulence of two Entomopathogenic Fungi as biological control agent on sugar beet fly, Pegomyia mixta in Egypt Der Pharma Chemica, 8(18):132-138.

Ellis, J. D.; J.R. Graham and A. Mortensen.(2013). Standard methods for wax moth research. J. Apic. Res. 2013, $52,1-17$

El-sheikh, M. F. M.(2003).Studied on the biological control of certain lepidopterous insects. M. Sc.Thes is, Fac. Agri.Tanta Univ. pp 127.

Goettel, M.S.; J. Eilenberg and T.R. Glare (2010). Entomopathogenic fungi and their role in regulation of insect populations. In: Gilbert, L.I., Gill, D.S. (Eds.), Insect Control: Biological and Synthetic Agents. Academic Press, San Diego, pp. 387.

Hussein, K. A.; M. A. Abdel-Rahman; A. Y. AbdelMallek; S. S. El-Maraghy and J. H. Joo.(2012). Pathogenicity of Beauveria bassiana and Metarhizium anisopliae against Galleria mellonella . Phytoparasitica 40(2): 117-126.

Ibrahim, A.A.; H. F. Mohamed; S. E. M. El- Naggar; M. A. Swelim and O. E. Elkhawaga.(2016). Isolation and Selection of Entomopathogenic Fungi as Biocontrol agent against the Greater Wax Moth, Galleria mellonella L. (Lepidoptera: Pyralidae) Egyptian Journal of Biological Pest Control, 26(2), 249-253.

Klingen, I.; R. Meadow and T. Aandal (2002). Mortality of Delia floralis, galleria mellonella and Mamestra brassica treated with insect pathogenic hyphomycetous fungi .J. Apple.Entomol., 126 (5); 231-237.
Krams, I.; S. Kecko; K. Kangassalo; F.R. Moore; E. Jankevics; I.; T. Krama; V. Lietuvietis; L. Meija; M. J. Rantala. (2015). Effects of food quality on tradeoffs among growth, immunity and survival in the greater waxmoth Galleria mellonella. Insect Sci, 22, 431-439.

Mansour, H. A. M. (1991). Studies on the natural enemies of honey bees. M.Sc. Thesis, Fac. Agri. Tanta Univ. pp199.

Mansour, H. A. M. (1999). Studies in the entomopathogenic fungus Beauveria bassiana as biological control agents for some economically important insects. Ph.D Thesis,Fac. Agric.Kafer E-Sheikh.Tanta Univ.pp.198.

Mansour, H. (2003). Microbial control by the fungus Beauveria bassiana against insect pests in honey bee storage. Mansoura Univ., J. Agri.Sci. (Egypt), Sep 2003, v. 28(9) p. 7059-7066.

Saleh, M.; M. Abdel-Raheem; I. Ebadah and H. E. Huda (2016). Natural Abundance of Entomopathogenic Fungi in Fruit Orchards and their Virulence against Galleria mellonella larvae. Egyptian Journal of Biological Pest Control 26(2): 203.

Soliman, M. O. M. (2005). The insecticidal effects of different neem formulations and Bacillus thuringien sis s ub-sp. aizawai on the Immature Stages of the Greater Wax Moth Galleria mellonella L.M.Sc.thesis. Fac. Agri. Univ. Khartoum, 81pp.

Tanada, Y. and H.K. Kaya, (1993). Insect pathology, Academic press, Inc, New York, NY.

Vey, A.; R.E. Hoagland and T.M. Butt (2001). Toxic metabolites of fungal biocontrol agents. In: Butt, T., Jackson, C., Magan, N. (Eds.), Fungi as Biocontrol Agents - Progress, Problems and Potential. CABI Press, Wallingford, UK, pp. 311-346.

Zimmermann, G. (2007). Review on safety of the entomopathogenic fungi Beauveria bassiana and Beauveria brongniartii. Biocontrol Sci. Technol. 17, 553-596.

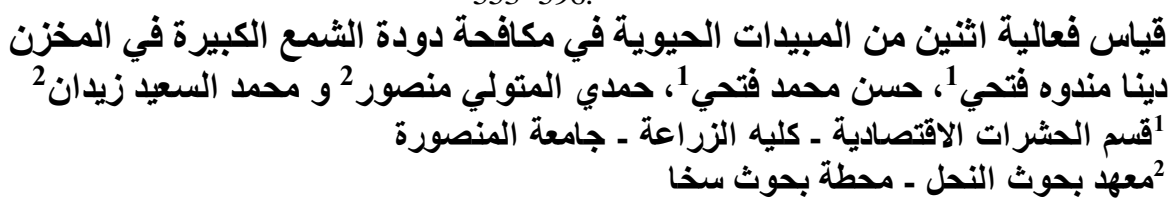

أجريت هذه الدر اسة لقياس فعالية اثثنين من المبيدات الحيو فية في مكافحة دودة الثمع الكبيرة في المخزن .و هما Beauvaria bassiana ومخلوط

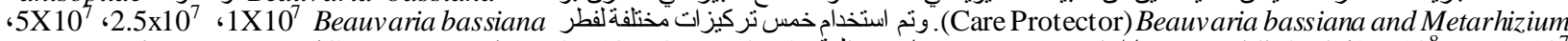

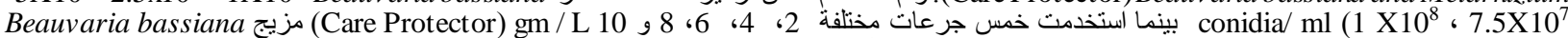

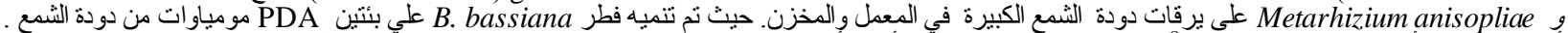

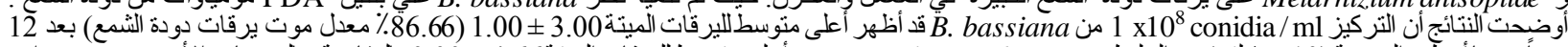

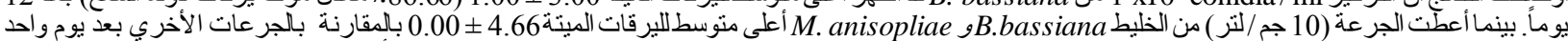

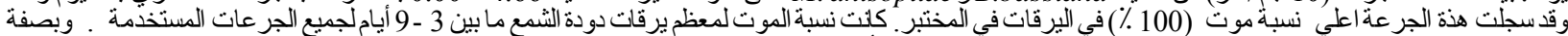

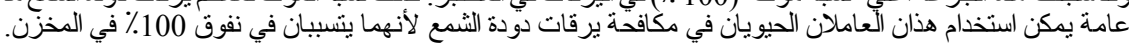

